\title{
Effect of Secondary School Categorization on Examination Failure Rates Among Public Secondary Schools Students in Kenya
}

\author{
Japhary Omari Nyangweso* \\ Kibabii University, PO Box 1699-50200 Bungoma \\ Julius K. Maiyo \\ Department of Educational Foundation, Planning and Management, \\ Kibabii University, P.o.box1699-50200 Bungoma \\ Robert Kati \\ Department of Science and Mathematics Education, \\ Kibabii University, P.o.box1699-50200 Bungoma
}

\begin{abstract}
Secondary schools in Kenya are categorized as national, extra-county, county, sub-county and private secondary schools. Students who excelled in K.C.S.E examination with a minimum grade of $\mathrm{C}+$ are allowed to pursue different courses in public and private universities. Others who scored $\mathrm{C}$ and $\mathrm{C}$ - grade joined diploma colleges. The paper sought to find out the effect of secondary school categorization on examination failure rates among public secondary schools students in Kenya. The scope of the study was limited to all the students from public secondary schools in the four counties of Kakamega, Bungoma, Busia, and Vihiga in Kenya. It was limited to randomly chosen sample size of 464 students, 58 principals, and 58 directors of studies from the 58 sampled out public secondary schools. Wellberg's (1981) theory of educational productivity was employed. The paper employed mixed methods and survey research design. Data collection instruments included questionnaires, interview schedules, focused group discussions and analysis of secondary data. Content validity was determined through subject matter expert review while reliability was determined through test-retest measures for consistency. Descriptive and inferential statistics were used to analyze data. Inferential one was the Kruskal Wallis test. The paper concluded that secondary school categorization led to failure of students in public secondary schools at KCSE examinations in Kenya due to academic inadequacies experienced in sub-county and some county public secondary schools. It was therefore recommended that the classification of students into the four distinct groups of national, Extra County, county and sub county students be abolished.
\end{abstract}

Keywords: academic achievement, Analysis, categorization, effect, Public secondary school

DOI: $10.7176 / \mathrm{JEP} / 10-33-03$

Publication date: November $30^{\text {th }} 2019$

\section{Introduction}

According to Tagharrobi (2012), one of the most important aspects of efficiency evaluation in education systems is the evaluation of academic failure and its familial and psychosocial outcomes for students. Bakouei (2010), classified them as personal, socioeconomic and educational. He further observed that the effect of factors such as high school average grade; educational background and entrance exam scores had been investigated in previous studies and found to impact greatly on students' academic achievement in high schools.

In a related research conducted in Jordan, Samer (2015) identified the causes and results of low academic achievement from teachers, parents and students' perspective as well as providing possible solutions to this problem. The researcher found out that there were weaknesses in the students' academic achievement. He further noted that the approach to teaching using traditional methods instead of using modern teaching methods, as well as the poor relationship between teachers and students had created a teaching environment lacking of respect which led to lack of students' acceptance of the learning process as whole.

Samer (2015) observed that even though, many parents complained of low academic achievement experienced by their children, they were in most cases unaware of the real reasons behind the weakness and ways to solve it. Some parents even used non educational and useless methods such as physical punishment to urge their children to be hardworking in their studies. Unfortunately, these coercive methods could not lead to improved conditions of their children. On the contrary, they only provided undesirable consequences.

Srinivas and Venkatkrishnan, (2016), investigated the effects of social interactions among students on academic performance in India. They noted that forming a social circle and friendships had a positive effect upon the academic outcomes of the students. This was important during the time when students had to work on a project or prepare for a test. The researchers further argued that group study was in most cases beneficial in 
helping students improve on their abilities. Srinivas and Venkatkrishnan (2016), also emphasized Psychological and Health Related Factors as being significant in determining students' academic performance in high school in India.

Radhika (2018) identified determinants of academic performance in students to include, class participation, class assignments, home-work assignments, tests, examinations, and participation in competitions or other events. He further observed that Secondary school students usually belonging to upper class and wealthy families performed better than those coming from poor economic backgrounds because they were assured of their academic aspirations being realized. It should however be noted that in almost all learning situations, student's attitude is a major factor contributing to low academic performance of a student.

Crosnoe (2012) observed that the "no pass, no play" policies in many school in several districts in the USA prevented students who had failed courses from participating in extracurricular activities, many of which had positive influences on adolescent development. According to Schiller (2013), the implementation of high stakes examination policies had broadened the consequences of academic failure beyond the student to stimulate greater interest among schools and teachers in students' academic outcomes. According to Barrington (2013), failure was an early indicator of potential dropout from school. The researcher linked this behavior to larger patterns of social inequality. In addition, Kaplan (2014) observed concerning students' academic performance in Houston that academic failure was a major determinant of status attainment and adult well-being. American Council on Education (2011) observed in its findings that high school dropouts, even those who obtained a General Equivalency Degree, had a substantially lower adulthood wages than high school or college graduates.

Maganga (2016) noted that Counselling and Guidance Services on public secondary schools had a significant role to play in the academic performance of secondary school students in Tanzania. In his research findings, Maganga, (2016), observed that there were numerous problems and difficulties that students experience while in school that may negatively affect their academic performance. Some may even get involved into violent and criminal acts, drug abuse, HIV, other sexually transmitted infections, teenage pregnancies and induced abortions. These factors had a direct impact upon not only their academic performance, but also their lives. He further found out that proper development of Study Skills and proper time management among secondary school students played a significant role in their academic performance.

In Kenya, research findings by Maina (2010) laid emphasis on School Resources. He observed that it was vital for secondary schools to make provision of resources that could be utilized to enhance the academic performance of students. The textbooks, notes, learning materials, hand-outs, technology, library facilities and laboratory facilities, especially in science subjects should include the essential materials. This will enable students to acquire a better understanding regarding academic concepts and how to perform the experiments.

Maina (2010) also considered Leadership Aspects in secondary schools as a major factor determining the nature of student performance. He observed that the principal, teachers and the administrative staff members of the school are vested with the authority to implement the managerial functions of planning, organizing, controlling, and directing the activities.

Kudari (2016) emphasized Classroom Environment. He observed that in Kenya and elsewhere in the world, academic concepts are made known to the students by the teachers within the classroom. Teachers had the main duty of completing the subject syllabus. Therefore, it was vital that classroom environment should be one with the highest level of discipline, and one that is well-ordered. Within the classroom, it was vital for the teachers and the students to implement the traits of morality and ethics. It was vital to promote mutual understanding, amiability and co-operation among the teachers and students as well as among the fellow students. Kudari (2016) also considered the Role of Parents as a factor influencing academic performance of students in Kenya's public secondary school students. Home was considered as the place from where the foundation of learning and education takes place. In order to produce good academic outcomes, it is vital for the parents, children and other family members to encourage a learning atmosphere within homes. Parents play an important role in leading to operative growth and development of their children. In schools, whatever problems that children go through regarding academics and other areas, they normally communicate to their parents. Parents are sources of security, encouragement and help their children in providing solutions to their problems. Parental involvement in the academic performance differ from one category of public secondary school to another. When parents invest substantially in the education of their children, the level of involvement will be high. This is seen during academic clinics in schools with parents in certain categories of public secondary schools being serious when it comes to the academic life of their children. They will promptly pay fees and be readily available whenever they are needed.

Satisfaction and happiness in one's student life (Kudari, 2016). Forming a social circle proves to be beneficial to the individuals in number of ways, such as, solving academic problems, getting involved in leisure activities, sharing one's joys and sorrows, and so forth. Research findings in Kenya revealed that poor academic performance in students with poor educational background was due to their unfamiliarity with effective learning strategies. According to KNEC report of 2017over 350000 candidates who sat the 2017 examinations scored 
grade D and below. An analysis of the results showed that 135550 candidates scored grade D, 179381 grade Dand 35536 candidates scored grade E. This was out of a total of 610501 candidates who wrote the papers. (KNEC, 2017). Compared to 2016, the report revealed that 295463 out of a total of 574125 candidates who sat the KCSE examinations scored grade D and below. A closer analysis of the report revealed that a majority of the learners came from sub-county and county schools especially those in rural areas. With the reality of Free Primary education, enrolments had increased and secondary schools expanded to take up this increased enrolment. . Besides continued numerical expansion of education opportunities, the Ministry of Education was keen on enhancing access and improving quality of education at all levels and training (Republic of Kenya, 2006). Thus in Kenya, the government was committed to developing her human resource by providing quality education to all her citizens in order to meet her manpower demands, eradicate illiteracy and improve standards of living The increased demand for secondary education had led to greater cost-sharing, resulting Despite the government's commitment to developing her human resources, certain disparities had been noted to affect the quality of education and overall performance in day-secondary schools located in many parts of the country. As a result of the disparities, the rural or low potential areas had been neglected despite the fact that they comprised 70 per cent of the country and 60 per cent of Kenya's population (Republic of Kenya, 2005). These variations in performance of secondary schools had raised a lot of concern because education is the key to creating, adopting and spreading knowledge. The gains in access to education had been unevenly distributed, with the poor seldom getting their fair share. A report by United Nations International Children and Education Fund, through the Republic of Kenya noted that, there was a distinct difference between the kind of education offered to the rich and the less privileged, with the latter being the majority of the population in the country (Republic of Kenya,2009). The United Nations (2001) noted that there was a pronounced rural-urban disparity in economic development in Kenya. This had mainly been the outcome of an underlying economic, ideological and sociocultural orientation that perceived rural areas as peripheral to urban areas. Consequently; there was a policy bias in favor of urban areas with the result that rural areas had been left behind in many spheres of development. Performance in KCSE had often varied depending on the location of the secondary schools. Despite schools having the same syllabus, disparities in performance had been noted every year in the Kenya Certificate of Secondary Education examinations. UNESCO (2011) explained that, most of the students from day-secondary schools ended up disadvantaged in a society, where academic qualifications were a prerequisite for higher learning or consideration for training, in government institutions and the private sector. Despite the need to expand the existing secondary school opportunities, by establishing day schools, the quality of education was to be maintained in these schools. The increase in expenditure on education was aimed at increasing enrollment, and enhancing access to education. Educational systems were to attempt to achieve maximum internal efficiency, through the management, allocation and use of resources available, to increase the quantity and quality of education. When retention is facilitated and achievement boosted, the efficiency of educational investment is achieved, (UNESCO, 2011). In Kenya, the demand for access to higher quality and more efficient secondary education is growing fast. This followed the introduction of free secondary education in 2008 (Republic of Kenya, 2010).

Asikhia (2010) observed that parental income was a major contributing factor to retention of students in schools, as it influenced their regular attendance. The higher the level of income per household, the higher the probability a school was to retain students. This allowed for effective syllabus coverage, thus enhancing school performance. The situation had partly been solved with the introduction of free day secondary school in 2017 by the government. But other levies still persisted to keep children out of school such as the cost of lunch and uniform. With these in mind, many students had been performing poorly in national examinations in Kenya and elsewhere in the world. The paper therefore sought to find out the effect of secondary school categorization on examination failure rates among public secondary schools students in Kenya.

\section{Methodology}

The paper employed Wellberg's (1981) theory of educational productivity. The paper employed mixed methods and survey research design. The study was conducted in four counties of Kakamega, Bungoma, Busia, and Vihiga in Kenya. The target population in this study was all the students from public secondary schools in the four counties. The sample size comprised of 464 students, 58 principals, and 58 directors of studies from the 58 sampled out public secondary schools. The study employed random and stratified sampling methods. Data collection instruments included questionnaires, interview schedules, focused group discussions and analysis of secondary data. Content validity was determined through subject matter expert review while reliability was determined through test-retest measures for consistency. Descriptive and inferential statistics were used to analyze data. Inferential one was the Kruskal Wallis test. 


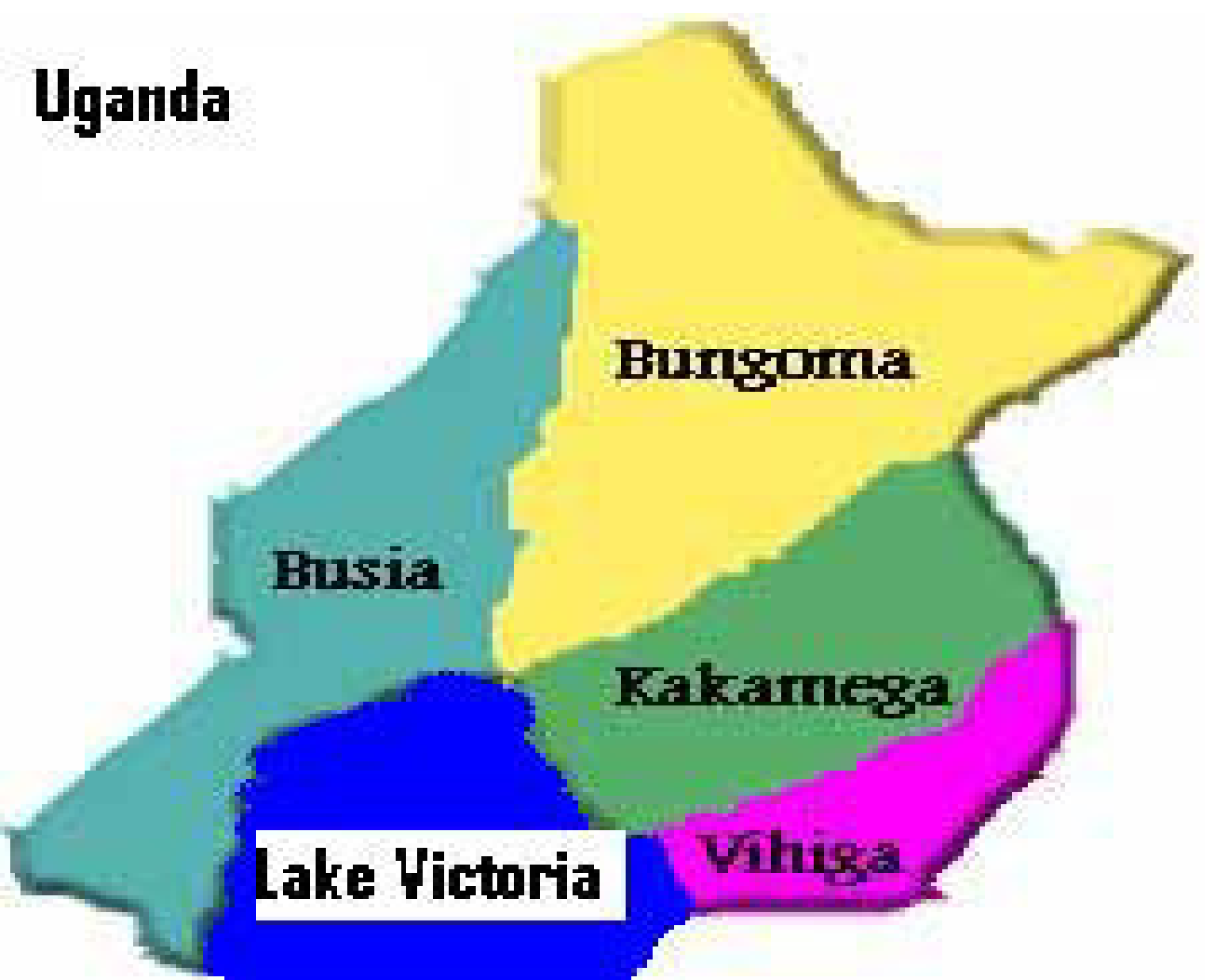

Figure 3.2: Map of the four counties of Kakamega, Bungoma, Busia and Vihiga

\section{Source: Kenya government}

\section{Results and discussions}

Table 1. Summary of responses on failure rates by students

\begin{tabular}{lcccrl} 
& More than once & Once & Not even once & Never & Total \\
\hline Male & 71 & 92 & 54 & 45 & 262 \\
Female & 58 & 71 & 36 & 37 & 202 \\
Total & 129 & 163 & 90 & 82 & 464 \\
\hline
\end{tabular}

\section{Source: The researcher (2019)}

From table 1. Above, 71 male and 58 female students acknowledged having failed in their internal examinations more than once, 92 male and 71 female students said they had failed once, while 54 male and 36 female students said that they had not failed even once. Another group of 82 students, 45 boys and 37 girls, was very categorical that they had never failed in their school exams.

To establish if there was a statistically significant difference in failure rates among students of different categories of public secondary schools in Kenya, a Kruskal Wallis test was conducted. To establish the effect of public secondary school categorization on failure rates, a questionnaire was administered to 464 form four public secondary school students and an interview to 58 principals and 58 directors of studies among the 58 public secondary schools in the four counties of Kakamega, Busia, Bungoma, and Vihiga. On a four point rating scale of more than once; once; not even once; and never; the 464 public secondary students were asked to give their ratings on a number of questions that were to give responses that were to determine their ratings on secondary school categorization and failure rates among learners in public secondary schools that they were enrolled. The respondents were to rate the frequency of failure in the exams they had taken since the time they were enrolled in form one.

To determine if the difference in failure rates among students in the four different categories of public secondary schools in Kenya was statistically significant, a null hypothesis which stated that "There was no statistically significant difference in the percentage failure rates among students of the four different categories of public secondary schools in Kenya" was tested. Using a Kruskal Wallis test, the responses from the 464 public secondary school students resulted in the following ranks as shown in table 2. 
Table 2. Ranks Table on responses from students on exam failure rates

\begin{tabular}{lcc}
\hline School category & $\mathrm{N}$ & Mean Rank \\
\hline County & 113 & 262.89 \\
Sub county & 190 & 220.86 \\
National & 57 & 208.74 \\
Extra County & 104 & 207.45 \\
Total & 464 & \\
\hline
\end{tabular}

\section{Source: The researcher (2019)}

From table 2. The responses from the 113 students in county public secondary schools were ranked highest, followed by the responses from the 190 students from the sub-county public secondary schools. The responses from the 57 students from the national public secondary schools was ranked third and in the fourth position was the rank on the responses of the 104 students in the extra county public secondary schools' students.

To prove if the ranks generated from the responses were statistically significant, a Kruskal Wallis test statistic was established as shown in table 3.

Table 3. Kruskal Wallis Test Statistics from students' responses on failure rates

\begin{tabular}{lc}
\hline Categorize & number of times failed exams \\
\hline Chi-square & 12.343 \\
Df & 3 \\
Asymp.sig & .006 \\
\hline
\end{tabular}

\section{Source: The researcher (2019)}

Since the p-value was less than 0.05 , the null hypothesis was rejected in favor of the alternative hypothesis. The findings therefore showed that there was a statistically significant difference in percentage failure rates among students of the four different categories of public secondary schools with $\chi 2(3)=12.343, p=0.006$, with a mean rank of 262.89 for county schools, 220.86 for the sub county schools, 208.74 for national schools and 207.45 for extra county public secondary schools. Students agreed that failure in national examinations was pegged on the category of secondary school that a student was enrolled in. Even though failure in national examinations cut across the four categories, it was more pronounced at Sub County and county school levels than at national and extra county school categories.

From the findings, the statistical difference in the percentage failure rates among students of the four different categories of public secondary schools was an indicator that categorization of public secondary schools determined to a bigger extent the failure rates among public secondary school students in Kenya. This was because failure in examinations among public secondary school students was disproportionally spread across the different categories of public secondary schools in Kenya based on their categories. Even though other factors were significant in determining the academic success of students in public secondary schools in Kenya, the category of a school had a significant role to play since the admission of students to form one class was based on performance at KCPE. Those who scored highly at KCPE joined the prestigious national and extra county public secondary schools leaving the ones who scored poorly in KCPE to join county and sub-county schools. These findings were similar to those of Ogundele (2014). According to the researcher, stakeholders had continued to trade blames on the causes of mass failure of students in public examinations. Some people shifted the blame on government, some on parents, some on society and students themselves with the teachers having the lion share of the blame. The quality of any educational system depended to a greater extent on the quality of teachers in terms of their academic and professional qualifications and experience as well as their level of competency and level of dedication to their primary function. National and extra county public secondary schools were adequately staffed and well equipped to allow effective learning and teaching. On the other hand, sub-county and county public secondary schools suffer from acute staffing and poor facilities which hinder quality academic performance among students enrolled. The difference in the magnitude of failure was significantly higher in students enrolled in sub county public secondary schools and county public secondary schools compared to those enrolled in Extra County and national schools. These findings were similar to those of Ogundele (2014 further observed that students' factors of poor academic performance were poor study habits, psychological adjustment problems, lack of interest in school programs, low retention, and association with wrong peers, low achievement motivation and emotional problems. Extra county schools and national schools had adequate manpower to reduce the effects of the mentioned factors as opposed to the situation in sub-county and county public secondary schools.

\section{Conclusion}

The paper concluded that secondary school categorization led to failure of students in public secondary schools at KCSE examinations in Kenya due to academic inadequacies experienced in sub-county and some county public secondary schools. This was because students who failed to score grades that could allow them join universities and diploma colleges were predominantly found spread across all the sub-county and county 
categories of public secondary schools. Even though examination failure of students was recorded in all categories of public secondary schools, the magnitude of failure was higher in the sub county and county schools compared to students in national and extra county schools.

\section{Recommendation}

The paper recommended that the classification of students into the four distinct groups of national, Extra County, county and sub county students be abolished. This classification created negative class systems which labeled some category of students as being superior to other categories especially those in Sub County and county schools. Besides this form of discrimination was against the education act and the supreme law of the land.

\section{REFERENCES}

Al-Zoubi, S. M., \& Younes, M. A. B. (2015). Low academic achievement: causes and results. Theory and Practice in Language Studies, 5(11), 2262-2268.

Asikhia (2010). Teaching the children of the poor, European Journal of Social Sciences, Lagos Nigeria.

Bakouei, F., Kheirkhah, F., Salmalian, H., \& Omidvar, S. (2010). Effective factors on educational status of midwifery students in Babol University of Medical Sciences. Strides in Development of Medical Education, 7(1), 44-50.

Estell, D. B., \& Perdue, N. H. (2013). Social support and behavioral and affective school engagement: The effects of peers, parents, and teachers. Psychology in the Schools, 50(4), 325-339.

Grabe, W., \& Kaplan, R. B. (2014). Theory and practice of writing: An applied linguistic perspective. Routledge.

Hicks, J. H., Kremer, M., Mbiti, I., \& Miguel, E. (2015). Vocational education in Kenya-A randomized evaluation. 3ie Grantee Final Report. New Delhi: International Initiative for Impact Evaluation (3ie).

Kapur, R. (2018). Factors Influencing the Students Academic Performance in Secondary Schools in India

Kim, Y. M. (2011). Minorities in higher education. American Council on Education, 23.

Kudari, J.M. (2016). Survey on the Factors Influencing the Student's Academic Performance. International Journal of Emerging Research in Management and Technology.

Lumpkin, A., \& Favor, J. (2012). Comparing the academic performance of high school athletes and non-athletes in Kansas 2008-2009. Journal of Applied Sport Management, 4(1).

Maganga, J.H. (2016). Factors Affecting Student's Academic Performance: A Case Study of Public Secondary Schools in Ilala District, Dar-es-salaam. University of Tanzania.

Maina, M.J. (2010). Strategies Employed by Secondary School Principals to Improve Academic Performance in Embu West District, Kenyatta University.

Ogundele (2014). Factors Associated with Poor Academic Performance in West African School Certificate Examination in Nigeria. University of Ibadan.

Radhika K. (2018). Factors Influencing the Students' Academic Performance in Secondary Schools in India. University of Delhi, India.

Tagharrobi. (2012) Survey of educational dropout indexes and their related factors in Alumni of paramedical faculty of Kashan Medical University, J. Babol University, Iran.

Walberg, J. (1981). A theory of educational productivity, Eric clearinghouse, Washington

Warrier, K. S., Schiller, J. H., Frei, N. R., Haftel, H. M., \& Christner, J. G. (2013). Long-term gain after teambased learning experience in a pediatric clerkship. Teaching and learning in medicine, 25(4), 300-305. 